\title{
REITER'S DISEASE IN THE FEMALE
}

\author{
BY \\ J. K. OATES \\ Whitechapel Clinic, London Hospital \\ AND \\ GEORGE W. CSONKA \\ St Mary's Hospital, London, W.2.
}

An increasing amount of interest is being shown in Reiter's disease and it is now recognized that the condition is commoner than was at one time believed. In many cases the complete triple syndrome does not occur, or is not recognized, as the ocular and genital components may be symptomless and escape detection unless specially looked for. The disease may be associated either with bacillary dysentery, non-specific diarrhoea, or a venereally acquired urethritis. These forms pursue a virtually identical clinical course and have been called the "dysenteric" and "venereal" syndrome by Harkness (1950a). A curious feature is that the dysenteric syndrome is apparently very rare in Great Britain (Corner, 1950) though it is commonly reported on the continent of Europe (Marche, 1954; Bourel, 1954; Paronen, 1948). Conversely, the "venereal" syndrome appears to be rare in Europe. All authorities agree that the "venereal" syndrome rarely affects the female, indeed some have gone so far as to deny its occurrence in women (Storm-Mathisen, 1946; Lofgren, 1946; Twiss and Douglas, 1946; Vallee, 1946). The existence of the dysenteric syndrome in women was noted, however, in the mid-19th century by Huette (1869).

Zewi (1947), in a paper dealing with the ophthalmological complications of Reiter's disease, described six cases in females. Young and McEwen (1947) recorded fourteen cases with the dysenteric syndrome, one in a woman. Paronen (1948) compiled the largest series of cases of Reiter's disease associated with an epidemic of bacillary dysentery, during the second world war in Finland, and of his 344 patients, 34 ( 9.9 per cent.) were women. The sex distribution of cases of dysentery in this epidemic is not stated, nor whether there was any difference in the clinical course of Reiter's disease in males and females. Harkness (1950b) could recall seeing only three female patients with polyarthritis, nongonococcal cervical discharge, and keratoderma. These were presumably examples of the venereally acquired syndrome. Rinkoff (1952) described in detail a woman who developed an attack of Reiter's disease with uveitis; there was no evidence of intestinal infection. Stanworth and Sharp (1956) reported on nine female patients whom they considered had Reiter's disease; three of these had radiographic changes of sacro-iliitis and suffered from attacks of recurrent uveitis. Dysentery was not considered to be an aetiological factor in these cases. More recently Refvem (1957) has reported three further cases.

\section{Material}

The present paper deals with case material from two venereal disease clinics in London; the Whitechapel Clinic of the London Hospital, and the Special Clinic, St. Mary's Hospital, Paddington. From the first clinic, ten female cases are reported, but no data on sex incidence are available; 110 cases of Reiter's disease in the male were studied, but these were selected for a variety of reasons. At St. Mary's Hospital, however, information has been collected from all the case records of patients of both sexes attending the clinic over a period of 15 years, and 213 cases of Reiter's disease were found. Of these, four ( 1.8 per cent.) were females. In all, therefore, fourteen cases in the female were available for study. Two patients had two attacks each (Cases 4 and 12); the others had single attacks.

\section{Clinical Data}

Age at Onset.-The range was from 18 to 58 years (mean 32.2).

Race.-All the patients were white, with the exception of Case 11, who was a West African.

Genital Infection.-Seven attacks of arthritis were associated with a gonococcal infection. In three further attacks (Case 4-second attack; Cases 8 and 14) there was presumptive evidence of gonorrhoea, but no bacteriological proof could be obtained. In the remaining six attacks (six patients) the genital infection was of the "non-specific" variety. In two of these cases vaginal discharge preceded the development of arthritis by some weeks; 
on examination both patients were found to have large cervical erosions. Two patients began their illness with cystitis, which was haemorrhagic in one case; $B$. proteus was grown from the urine in one patient, but in the other no growth was obtained. In Case 5 no genito-urinary symptoms were noted by the patient until the arthritis had been present in chronic form for 8 years, when she developed cystitis with haematuria and an exacerbation of her arthritis; she was then found to have chronic cervicitis.

Arthritis.-This was present in all cases and in every attack. The joints involved are shown in Table I. In five attacks it was mono-articular, the single joints affected being the knee and shoulder (twice each) and the wrist.

TABLE 1

DISTRIBUTION OF JOINTS INVOLVED

\begin{tabular}{|c|c|}
\hline Joints Involved & Number of Patients Affected \\
\hline $\begin{array}{llll}\text { Knees } & \ldots & \ldots & \ldots \\
\text { Wrists } & \ldots & \ldots & \ldots \\
\text { Ankles } & \ldots & \ldots & \ldots \\
\text { Metatarsophalangeal Joints } \\
\text { Shoulder } & \ldots & \ldots \\
\text { Sacro-iliac Joints } & \ldots \\
\text { Metacarpophalangeal Joints }\end{array}$ & $\begin{array}{r}11 \\
7 \\
6 \\
5 \\
5 \\
3 \\
1\end{array}$ \\
\hline
\end{tabular}

The response to treatment with penicillin was of interest. This drug was administered to all patients in whom gonorrhoea had been diagnosed or the presumptive evidence of infection was strong (ten cases in all). One further patient was given the drug on no very clear grounds. In only one case (Case 3) did the arthritis show any improvement after treatment with penicillin. It is possible, therefore, that this patient may have been suffering from a true gonococcal arthritis.

In two cases, in which the disease pursued a long and chronic course, therapy of all kinds, including steroid hormones and butazolidin, appeared to offero no benefit.

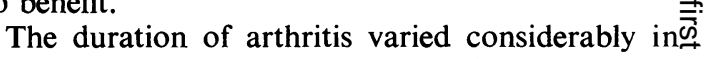
sixteen attacks. Details are shown in Table II.

DURATION OF ARTHRITIS IN SIXTEEN ATTACKS

\begin{tabular}{|c|c|}
\hline Duration & Number of Attacks \\
\hline $\begin{aligned} 2 & \text { mths } \\
2-8 & \text { mths } \\
1-2 & \text { yrs } \\
6 & \text { yrs } \\
10 & \text { yrs }\end{aligned}$ & $\begin{array}{l}5 \\
6 \\
3 \\
1 \\
1\end{array}$ \\
\hline
\end{tabular}

Fasciitis and Tendonitis.-Plantar fasciitis occurred in four cases. Achilles tendonitis and involvement $t_{-}^{\infty}$ of the extensor tendons of the wrist were seen ini one case each.

Eye Involvement.-In seven of the fourteen cases, eye changes were noted. Four patients developed conjunctivitis during their illness, which was coms plicated in one case by the development of super-? ficial keratitis. Two patients (Cases 7 and 14) developed recurrent iritis over a period of 2 years 5 One patient had an ulcer of the eye, presumably of the cornea, but this was treated elsewhere ando no records are available.

Skin and Mucous Membrane Lesions.-No evi-? dence of these was found in any of the cases.

Radiological Changes.- $X$-ray examination of clinically affected joints and routine films of the heels and sacro-iliac joints were carried out in eight cases. Changes in the sacro-iliac joints with losș. of the normal articular outline and subarticulativ sclerosis were seen in Case 11 (Fig. 1) and also in a less marked degree in Cases 5 and 6.

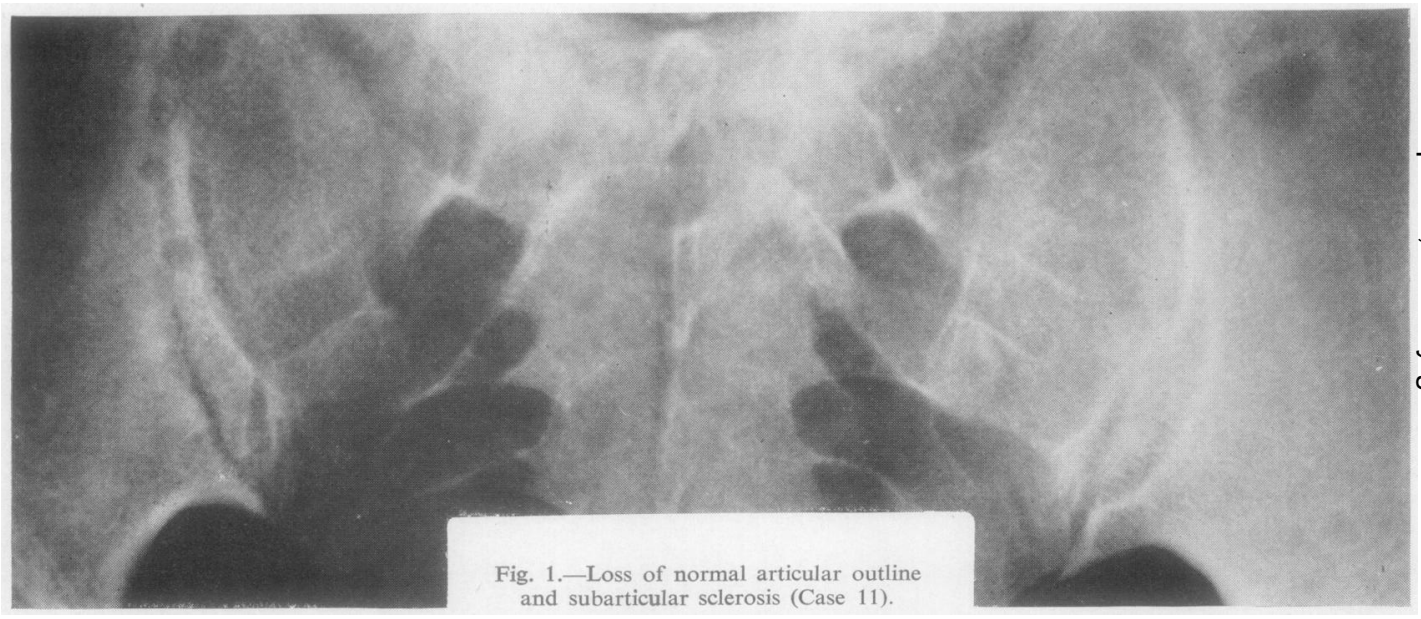




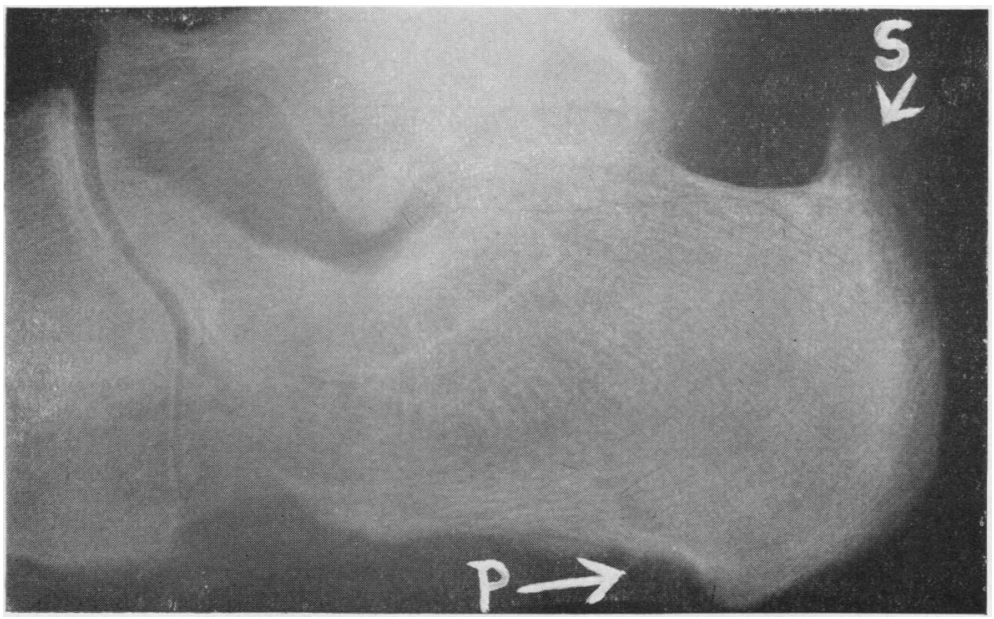

Fig. 2.-Plantar periostitis (P) and posterior spurring (S) of os calcis (Case 5).

Posterior and plantar spurring was present in Case 5 (Fig. 2). Small plantar spurs were present in Cases 6, 11, and 12. Periosteal new bone formation, erosions, and cystic changes in the metatarsal bones were found in Cases 6, 12, and 13. Marked periosteal involvement of the patella and adjacent femur was seen in Case 11 (Fig. 3).

Laboratory Findings.-These are summarized in Table III (overleaf). Pleuropneumonia-like organisms (P.P.L.O.) were cultured from the cervices of two patients and a complement-fixation test for P.P.L.O. was positive in a third case. The differential sheep cell agglutination test (Rose-Waaler) was performed in six cases, including three which ran a protracted course, and was negative in all six. The differential blood count was normal in all except two cases in which it was not done. A rectal swab 'grew no dysentery organisms' in three cases and dysentery agglutinations in four 'further cases were all negative'.

\section{Case Reports}

Case 1, a single female aged 18, complained of pain and swelling in left knee for 3 days and vague lower abdominal pain of 6 weeks' duration. She denied any genito-urinary symptoms. On examination she had a severe cervicitis, proctitis, and bilateral salpingitis. The left knee was tensely swollen. Gonococci were found in smears from the cervix and rectum. She was admitted to hospital and treatment with intramuscular crystalline penicillin was instituted, a total of 2.4 mega units being given in 7 days. The arthritis of the knee showed no improvement though the salpingitis and cervicitis resolved

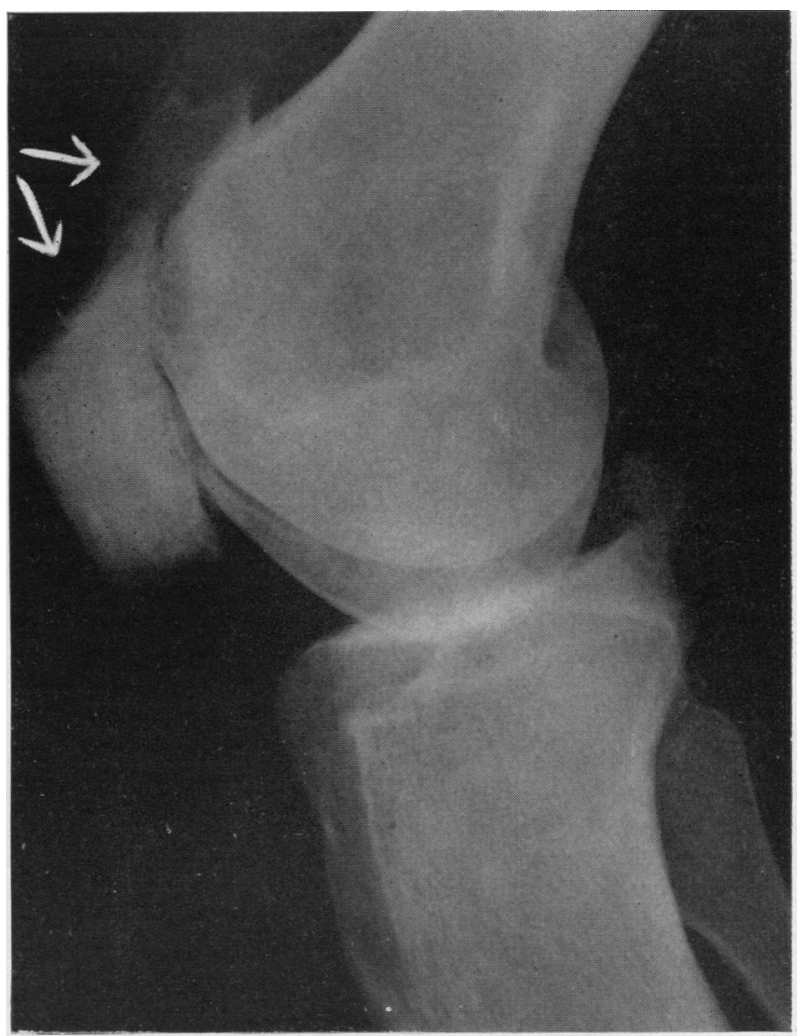

rapidly. She was then given artificial fever therapy by means of subcutaneous "Pyrifer" vaccine. The arthritis then commenced to improve and there were no abnormal signs to be found in the left knee 6 weeks after admission. $X$ ray showed no abnormality. 
TABLE III

PATHOLOGICAL FINDINGS IN FOURTEEN WOMEN WITH REITER'S DISEASE

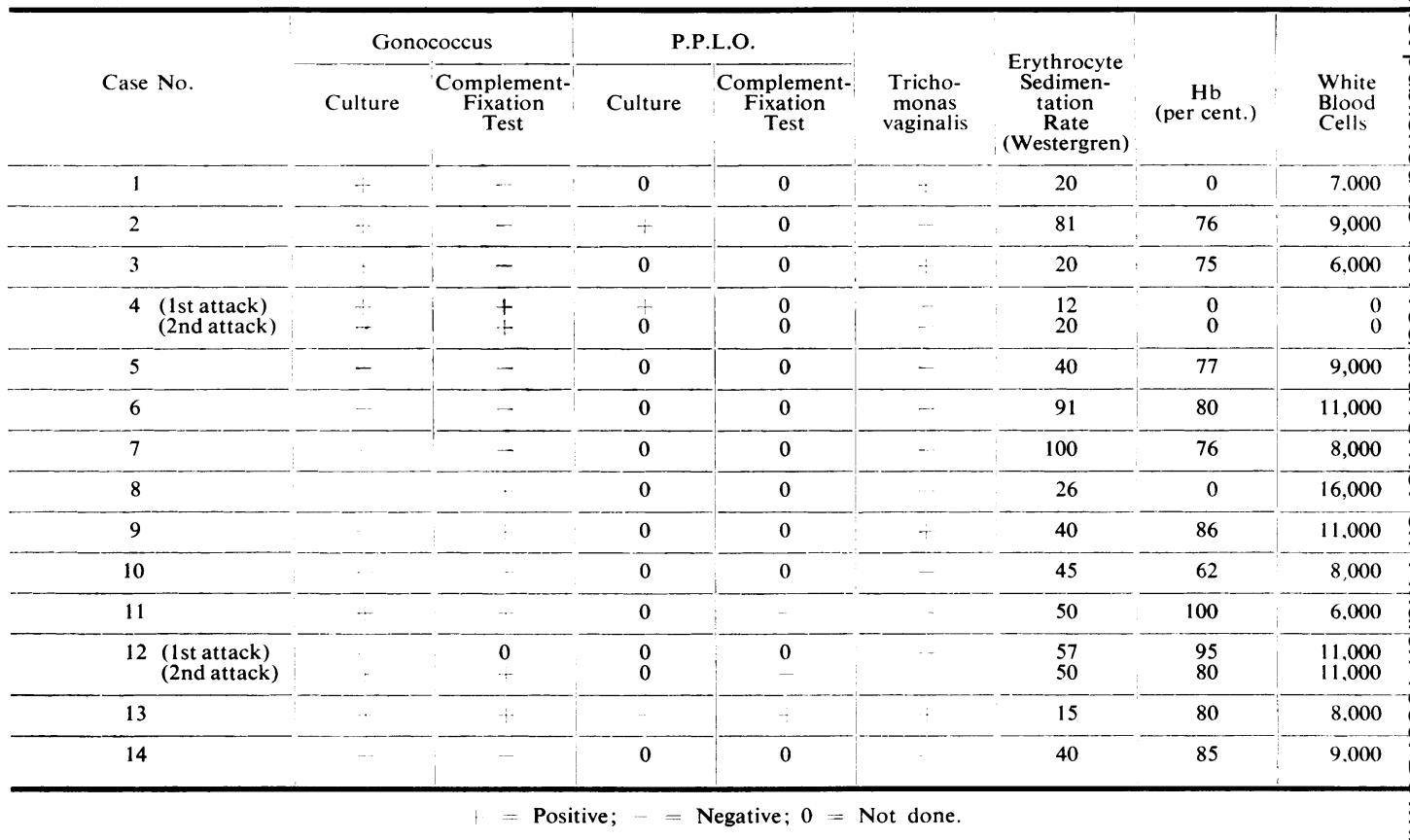

Case 2, a married housewife aged 19, had developed a vaginal discharge 3 months after marriage, and 4 weeks later the left wrist became swollen and painful. Examination showed an acute arthritis of the left wrist and the presence of a severe vaginitis, urethritis, and cervicitis with erosion. The body temperature was $101^{\circ} \mathrm{F}$. Cultures from the cervix and urethra were positive for gonococci and pleuropneumonia-like organisms. She was admitted to hospital and treated with 600,000 units procaine penicillin intramuscularly daily for 8 days. There was no immediate response to this treatment, but the joint began to improve after about a week, and cleared completely in a month. She was febrile for 8 days. The erythrocyte sedimentation rate was 81 $\mathrm{mm} . \mathrm{Hg}$ in one hour (Westergren) and the haemoglobin 76 per cent. $X$ ray of the wrist and sacro-iliac joints showed no abnormality.

Since leaving hospital she had had five attacks of gonorrhoea and one attack of "cystitis", but on no occasion did any joint symptoms develop.

Case 3, a married housewife aged 36, complained of pain in both wrists for 4 days. There were no genitourinary symptoms. She had an acute arthritis of the left wrist and a teno-synovitis of the extensor tendons of the right wrist. Genital examination showed some urethritis and cervicitis, and gonococci were present in smears and cultures from these sites. The patient was admitted to hospital and treatment with procaine penicillin injections 600,000 units daily and sulphatriad
5 g. daily by mouth was begun. The teno-synovitio improved on the fourth day in hospital, but the arthritis of the wrist did not clear up for a further 3 days. During a follow-up period of 8 months the patient remaine $\bar{B}$ free of all symptoms.

Case 4, a married housewife aged 37, had noted vaginal discharge for 7 days, and 3 days before attending had developed lower abdominal pain, pain in the righishoulder, and sore eyes.

She was found to have bilateral conjunctivitis and arg acute arthritis of the right shoulder joint. Genitas examination revealed the presence of a purulent urethritis and cervicitis, both fallopian tubes being thickened an acutely tender. Smears and cultures were positive fop gonococci. After admission to hospital she was treatedE. with 600,000 units procaine penicillin intramuscularly for 10 days. There was no improvement in the arthritis though the abdominal pains and conjunctivitis rapidls subsided. She was eventually subjected to artificial fevet therapy by means of subcutaneous "Pyrifer" vaccine $\sigma$ but this also seemed to have little effect. The joink recovered in about 4 weeks' time.

A year later she attended again, this time complaining of lower abdominal pain and pain in the right shouldef for about 16 days. She had attended another hospitaए for the abdominal pain, where she had received "elec웅 trical treatment", and 2 days before attending at the clini邑 she had developed vaginal discharge and scalding anco frequency of micturition. She had an acute arthritis 
of the right shoulder joint, a purulent urethral and cervical discharge, and tender swelling of both fallopian tubes. Smears and cultures were negative for the presence of gonococci but the gonococcal complementfixation test was positive.

She was again admitted to hospital and procaine penicillin 600,000 units daily was given for 10 days by intramuscular injection. Again the arthritis made no response to this treatment though the genito-urinary and abdominal symptoms were quickly relieved. The arthritis subsided gradually, however, and no signs of disease of this joint was present 4 weeks later. She was seen from time to time over a 4-year period, during which she contracted gonorrhoea on four occasions. She had no further arthritic symptoms and no radiographic changes were noted.

Case 5, a married housewife aged 37, gave the following history:

1946: Normal pregnancy and delivery.

1947: Pain in the plantar surface of both heels, not very troublesome except after a lot of walking.

1948: The left ankle became swollen and painful; this lasted a few months and then cleared up only to recur about 14 weeks later. It persisted in this fashion for nearly 2 years.

1951: Pain and swelling of the left knee developed; it waxed and waned in severity, but in general persisted for the next 4 years.

1955: The right knee became swollen and painful. A few months later dysuria, frequency, and haematuria developed, associated with a low grade arthritis of several metatarsophalangeal joints of both feet. The patient felt well throughout the illness.

Both knee joints were slightly painful and there was a small effusion in the left one. There was some thickening of the left ankle joint and tenderness to pressure over the plantar surface of both heel bones. There was a moderate degree of pes planus with early lateral deviation of the toes at the metatarsophalangeal joints. Genital examination revealed a chronic cervicitis. Smears and cultures were negative for gonococci and the complementfixation test was negative. A biopsy of the cervix showed only "non-specific chronic inflammatory changes". A catheter specimen of urine showed no abnormality (the patient had received treatment for her presumed "cystitis" from her own doctor before admission). The haemoglobin was 80 per cent., the erythrocyte sedimentation rate $40 \mathrm{~mm}$./hr (Westergren) and the blood uric acid $3.2 \mathrm{mg} . / 100 \mathrm{ml}$. The Rose-Waaler test was negative.

$X$ rays of the wrists and hands showed a small erosion of the right ulna styloid but no other changes. The right sacro-iliac joint was probably abnormal, showing widening and sclerosis of the iliac portion of the base. The ankles showed periosteal new bone formation on both malleoli. Erosions were present in all the metatarsal heads of the left foot. The upper posterior surface of both calcanei showed a partly destructive and proliferative lesion. There was periosteal new bone formation on the plantar surface of both of these bones, particularly the left.
The patient's symptoms, which were not severe, were controlled to some extent by oral phenylbutazone.

Case 6, a married housewife aged 52, enjoyed good health until September, 1956, when she had a severe attack of cystitis treated by her own doctor. In February, 1957, and March, 1957, she had attended an Eye Hospital for the treatment of attacks of conjunctivitis, and 6 months later she developed dysuria, urgency, and terminal haematuria. She was seen in the Surgical Out-Patients Department and a diagnosis of cystitis made. A catheter specimen of urine grew Bacillus proteus on culture. She received treatment with sulphonamides by mouth, and the urinary symptoms improved. She then began to complain of pain in the region of the left buttock and in the lumbar region and of feeling generally ill. An irregular fever of up to $101^{\circ} \mathrm{F}$. persisted for the next 3 weeks. Arthritis of both knee joints and numerous metatarsophalangeal joints developed; this persisted for about 21 days and then began to improve spontaneously; 8 weeks after the onset of joint symptoms she had a further attack of frequency and dysuria which was associated on this occasion with bilateral conjunctivitis and an exacerbation of the back pain.

Examination showed effusions into both knee joints and tenderness of all metatarsophalangeal joints and of the plantar surface of both heels. Compression of the anterior superior iliac spines produced pain referred to the region of the left sacro-iliac joint. Genital examination showed the presence of a moderate severe cervicitis. Smears and cultures were negative for the presence of gonococci. The erythrocyte sedimentation rate was $90 \mathrm{~mm}$./hr. Fluid aspirated from the right knee was yellow and turbid. The deposit contained many pus cells and occasional lymphocytes; culture was sterile. The Rose-Waaler test was negative on two occasions.

The arthritic pain was not relieved by phenylbutazone, but the arthritis made a slow recovery over a period of about 6 months.

Case 7, a married housewife aged 35, was well until she suffered a prolonged attack of iritis 3 months after the birth of her third child. Eventually both eyes were involved and recurring attacks persisted for about 2 years, when a profuse yellow vaginal discharge with some dysuria developed. A few days later the right knee became swollen and painful. Examination showed an acute iritis of the right eye, and the right knee joint was tense and swollen and all movements limited by pain. There was a severe cervicitis with erosion. Smears and cultures from the cervix and urethra were negative for gonococci. Turbid yellow fluid was aspirated from the knee joint and smears showed many pus cells and some lymphocytes. No organisms were seen and the fluid was sterile after both aerobic and anaerobic cultures. The gonococcal complement-fixation test was negative and the haemoglobin 76 per cent. Treatment with intramuscular streptomycin improved the vaginal symptoms but had no effect on the arthritis. Oral cortisone $50 \mathrm{mg}$. twice daily for 2 weeks caused lessening of pain and swelling 
in the right knee. The dose of cortisone was progressively reduced over the next 2 weeks but the improvement in the knee joint was maintained. The iritis was still active, however, and did not clear up for a further 2 months. 6 months later there was a return of the vaginal discharge associated with a further attack of iritis and a return of pain and swelling in the right knee joint. These symptoms persisted for nearly 6 months, except that the vaginal discharge again showed improvement after streptomycin therapy. Shortly afterwards, the arthritis slowly began to improve. No nodules were found and the lowest haemoglobin value recorded was 76 per cent. The Rose-Waaler test was negative and the erythrocyte sedimentation rate varied from $90 \mathrm{~mm}$./hr at the height of the illness to $6 \mathrm{~mm}$./ hr during the stage of remission. The illness lasted for about 3 years and evidence of a low grade arthritis of the right knee was still present at the patient's last attendance.

Case 8, a single female aged 27, had developed a swollen painful right wrist and right ankle 6 months before attendance at the clinic, and had been admitted to another hospital where a diagnosis of infective arthritis was made. The erythrocyte sedimentation rate was $20 \mathrm{~mm}$./ hr and the gonococcal complement-fixation test was positive. She had received treatment with intramuscular penicillin 4-hrly for 7 days but details of the dosage were not available. There was no response to this therapy but some improvement occurred later after rest in bed. She was eventually referred to the clinic on account of the serological findings, and was then complaining only of slight pain in the right wrist.

On examination there was slight tenderness and swelling of the right wrist joint. Genital examination showed the presence of a moderately severe cervicitis with erosion. Smears and cultures were repeatedly negative for the presence of gonococci, but the gonococcal complementfixation test was strongly positive. The erythrocyte sedimentation rate was $27 \mathrm{~mm}$./hr. A trial of fever therapy by means of intramuscular Pyrolactin produced no effect on the arthritis which gradually improved, subsiding completely in about 12 months' time.

Case 9, a single female aged 19, developed an "ulcer at the angle of the eye" after sexual intercourse with a casual acquaintance. She had been treated with eye drops at another hospital but no details were available. A week later she had developed a vaginal discharge with some frequency, and 3 days later her right knee and ankle became swollen and painful, and this was followed by similar symptoms in the right wrist.

Examination revealed an acute arthritis of the right ankle, wrist, and knee joint. The body temperature was $101^{\circ} \mathrm{F}$. and the pulse rate 100 . A cervical culture was negative for the presence of gonococci. She received treatment with crystalline penicillin, 250,000 units intramuscularly twice daily, and oral sulphonamides ( 5 g. daily). Genital examination after 2 days of this treatment showed a moderate degree of vaginitis and cervicitis. No gonococci were found in smears and none were grown in culture. Many trichomonas were present in the vaginal smear. The arthritis made no response to chemotherapy but began to improve about 2 week after admission. The erythrocyte sedimentation rate was $40 \mathrm{~mm}$./hr and the haemoglobin 83 per cent. The gonococcal complement-fixation test was negative.

After discharge from hospital the patient had three attacks of gonorrhoea but experienced no further join symptoms.

Case 10, a married housewife aged 23, had developeč dysuria, frequency, and vaginal discharge 5 days beforeadmission, 3 days later the right shoulder became? painful to move, and the next day the left wrist became swollen and painful.

She looked ill and was in severe pain, with body temperature $100 \cdot 4^{\circ} \mathrm{F}$., and pulse rate 88 . There was an acute arthritis of the left wrist and right shoulder with $\overrightarrow{0}$ restriction of all movements by pain. Genital examina-tion revealed a purulent urethritis, vaginitis, and cer vicitis with erosion. Smears and culture were positive for gonococci from the urethra and cervix. She receivedP an injection of 1 mega unit crystalline penicillin intramuscularly and was then admitted to hospital, wherל్ procaine penicillin 600,000 units intramuscularly waş given daily for 5 days. The fever continued and there was no improvement in her arthritis. Following treat $\overrightarrow{0}$ ment with $25 \mathrm{mg}$. ACTH intramuscularly every 6 hours the joint condition improved rapidly and the pain subsided. The injections were stopped after 6 day\$ and there was an immediate return of pain and swellings in the shoulder and wrist and the temperature rose to. $100^{\circ} \mathrm{F}$. Penicillin 600,000 units intramuscularly dailjo was resumed without apparent effect. She remaineo in hospital for 6 weeks and on discharge the joints were normal, the erythrocyte sedimentation rate was $60 \mathrm{~mm}$. ? hr falling to $20 \mathrm{~mm}$./ hr, and an $x$ ray of the affected joints showed no abnormality.

Case 11, a single West African female aged 26, waș admitted to hospital with gonococcal salpingitis; 3 weeks after penicillin treatment she developed arthritis of both knees, and the right ankle, right hip, and left shoulder. Penicillin in large doses had no effect on the course of the arthritis which persisted with little change for 3 years? At that time she began to complain of pain and morning stiffness in the neck and lower back. During the follow ing year the joints improved when she had an attack of bilateral conjunctivitis; 3 months later and one yea later the conjunctivitis recurred. When she was las seen, $7 \frac{1}{2}$ years after the onset of her illness, she was quite well, except for occasional discomfort in the lumbas region. $X$-ray examination showed marked change $\omega$ in the knee joints and right sacro-iliac joint (Fig. 3).

Case 12, a married female aged 49, had attendeç్ another hospital with a vaginal discharge which was followed within 2 weeks by arthritis involving the ankles, right wrist, several metatarsophalangeal joints, and the cervical spine. Genital investigation failed to show the्D gonococcus. This attack lasted 4 months, and 3 year later the patient again noticed a vaginal discharge 
followed 2 weeks later by bilateral conjunctivitis, and 2 days later by polyarthritis and plantar fasciitis. The body temperature rose to $103^{\circ} \mathrm{F}$. during the first 3 days of the arthritis, and the white blood count was 11,000 per c.mm. with 81 per cent. neutrophils. Genital examination showed cervicitis from which gonococci were grown. Penicillin had no effect on the arthritis, which lasted for about 2 months, but was successful in clearing the gonorrhoea. During this time the eyes again became inflamed and dendritic corneal ulcers developed. When seen 3 months later, she had completely recovered, but $x$ rays showed periosteal new bone formation around the neck of the third left metatarsal and small bilateral calcaneal spurs.

Case 13, a married female aged 25, gonorrhoea from her husband and remained untreated for 3 months, 2 weeks after she first noticed the vaginal discharge, she developed pains in both shoulders and the lower back, which lasted for 6 months and was not influenced by penicillin therapy. She had three attacks of gonorrhoea without any complications 3 years later, and a year later cystitis developed. The urine was sterile on bacteriological investigation. A month later extensive polyarthritis, Achilles tendonitis, and sacro-iliitis developed. On genital examination urethritis and cervicitis was found but neither gonococci nor P.P.L.O. were grown. The arthritis did not respond to penicillin or prednisone $20 \mathrm{mg}$. daily for 4 weeks, but phenylbutazone $400 \mathrm{mg}$. daily appeared to relieve the symptoms. At present the disease is still active in the joints, some 5 years after the onset. There was no anaemia during the course of the illness. $\quad X$ rays showed some erosions of the metatarsal bones on both sides; the other joints, including the sacroiliacs, appeared to be normal.

Case 14, a married woman aged 58, gave a history of vaginitis, followed within a month by arthritis involving the right knee and several toes, and plantar fasciitis on the right side. A month later iritis developed and this had recurred several times over the next 2 years. Gonococci were not isolated from the genital tract and the arthritis did not respond to intramuscular penicillin injections. At present, 2 years after the onset of the arthritis the patient is convalescing.

\section{Discussion}

The course of the arthritis in two patients (Cases 5 and 11) was of much longer duration than the others, and persisted for approximately 10 and 6 years respectively. Such chronicity suggests the possibility of rheumatoid arthritis as an alternative diagnosis. This is considered unlikely, however, as in Case 11 the onset was closely associated with genital infection, attacks of conjunctivitis occurred during the illness, and radiographic changes typical of Reiter's disease developed in the right sacro-iliac joint, patella, and adjacent tibia (Figs 1 and 3). No rheumatic nodules were present and the Rose-
Waaler test (D.A.T.) was negative. In Case 5 the association with genital disease was less clear. However, the deformity of the feet was characteristic of Reiter's disease as was the development of the plantar periosteal reaction (Fig. 2) and other typical radiographic changes (Mason, Murray, Oates, and Young, 1959). No rheumatic nodules were found and the Rose-Waaler test was negative. Neither patient showed the malaise, weight loss, and other evidence of systemic reaction which is seen so commonly in young women with rheumatoid arthritis.

In seven patients gonococci were cultured from the genital tract, and in three of them (Cases 1, 2, and 4) the arthritis was mono-articular. Though no joint and fluid studies were carried out in these patients the complete lack of response to adequate courses of intramuscular penicillin was strong evidence against the possibility that the arthritis was gonococcal.

The truth of the statement that Reiter's disease is uncommon in the female appears to be confirmed by our experience. In none of the fourteen patients was there any evidence of intestinal infection and the association of the attacks with gonorrhoea on seven and possibly ten occasions, makes it likely that all were examples of the venereally acquired syndrome. Some of these patients had multiple genital infections and not every attack was followed by arthritis. Why the disease should attack the male in the majority of instances is an unsolved problem. Men in general tend to be more promiscuous sexually than women and would therefore be more likely to acquire the venereal form of the disease in greater numbers. There is, however, no evidence at present that Reiter's disease occurs more commonly amongst prostitutes than among women generally. In addition, although the female contacts of patients with Reiter's disease are frequently found to be suffering from non-specific genital infection, they rarely, if ever, are found to be suffering from arthritis or uveitis. Possibly the degree of disproportion is more apparent than real; for example, in this series, the genito-urinary symptoms included vaginal discharge, dysuria, and frequency of micturition, but complaints of this nature are common, especially in parous women, and do not always lead to medical investigation. The possibility that female patients with Reiter's disease may be diagnosed as suffering from other rheumatic diseases should not be discounted.

With such a small series of patients, it is not profitable to make many comparisons about the course of the disease in the two sexes. However, the general pattern seen in the male patients was 
also observed in the females, including some in which the disease pursued a prolonged chronic course. Possibly, mono-articular forms were commoner than might have been expected from the experience in male patients. Csonka (1958), for instance, found that 7 per cent. of his 209 male patients had one joint involved, against 31 per cent. in the present series. Clinical evidence of sacro-iliitis was found in two cases and radiographic changes, identical with those described in men (Murray, Oates, and Young, 1958; Reynolds and Csonka, 1958) were found in three others.

\section{Summary}

(1) The literature relating to Reiter's disease in the female is briefly reviewed.

(2) Fourteen cases of Reiter's disease in the female are described, and the clinical course and accessory findings are shown to be similar to those seen in males.

(3) The incidence of Reiter's disease in females compared with that in males is low, though the possibility of misdiagnosing such cases is probably higher than in the male.

This work was carried out under the aegis of the Medical Research Council Working Party on NonSpecific Urethritis, with the aid of a grant from the U.S. Public Health Service. We wish to thank Mr. Ambrose King and Dr. G. L. M. McElligott for their help and for permission to use the case material.

\section{REFERENCES}

Bourel, M. (1954). Rev. rhum., 21, 249

Corner, B. D. (1950). Arch. Dis. Childh., 25, 398.

Csonka, G. W. (1958). Brit. med. J., 1, 1088.
Harkness, A. H. (1950a). "Non-Gonococcal Urethritis", p. 99 Livingstone, Edinburgh. (1950b). Ibid., p. 102-3.

Huette, -. (1869). Arch. gén. Méd., 2, 132

Löfgren, S. (1946). Nord. Med., 29, 321.

Marche, J. (1954). Rev, rhum 21, 321. Mason, R. M., Murray, R. S., Oates, J. K., and Young, A. C. (1959)

Murray, R. S., Oates, J. K., and Young, A. C. (1958). J. Fac

Murray, R. S., Oates, J. K.

Paronen, I. (1948). Acta med. scand., Suppl. 212, p. 40

Refvem, O. (1957). Acta rheum. scand., 3, 282. Reynolds, D. F., and Csonka, G. W. (1958). J. Fac. Radiol. (Lond.)

Rinkoff, S. (1952). J. Amer. med. Ass., 148, 740.

Stanworth, A, and Sharp, J. (1956). Ann, rheum, Dis $15,140$.

Storm-Mathisen, A. (1946). Acta derm-venereol. (Stockh.), 26, $547 \overrightarrow{0}$

Twiss, J. R., and Douglas, A. H. R. (1946). Ann. intern. Med.; 24, 1043 .

Vallee, B. L. (1946). Arch. intern. Med., 77, 295.

Young, R. H., and McEwen, E. G. (1947). J. Amer. med. Ass. 134, 1456.

Zewi, M. (1947). Acta ophthal.(Kbh.), 25. 47.

\section{La maladie de Reiter chez la femme}

\section{RÉSUMÉ}

(1) On passe en revue la littérature concernant la v maladie de Reiter chez la femme.

(2) On décrit 14 cas de maladie de Reiter chez la femme et on montre que l'évolution clinique et les données accessoires sont les mêmes que chez l'homme.

(3) La fréquence de la maladie de Reiter chez la femme en comparaison à l'homme, est basse, bien que la possibilité d'une erreur diagnostique en tels cas est probable $\overrightarrow{\vec{c}}$ ment plus grande que chez les hommes.

\section{La enfermedad de Reiter en la mujer} SUMARIO

(1) Se pasa en revista la literatura respecto a $1 \frac{5}{5}$ enfermedad de Reiter en la mujer.

(2) Se describen 14 casos de enfermedad de Reiter erf mujeres y se demuestra que la evolución clínica y loß datos accesorios se parecen a los del hombre.

(3) La incidencia de la enfermedad de Reiter en la mujer, comparada con la en el hombre, es baja, aunque la posibilidad de un error diagnóstico en tales casos es: probablemente mayor que en el hombre. 